\title{
The Neutrophil-Lymphocyte Ratio Is Associated with Coronary Artery Calcification in Asymptomatic Korean Males: A Cross-Sectional Study
}

\author{
Su-Hyun Nam, ${ }^{1}$ Sung-Goo Kang, ${ }^{1}$ and Sang-Wook Song ${ }^{1,2}$ \\ ${ }^{1}$ Department of Family Medicine, St. Vincent's Hospital, College of Medicine, The Catholic University of Korea, \\ Suwon, Republic of Korea \\ ${ }^{2}$ Health Promotion Center, St. Vincent's Hospital, College of Medicine, The Catholic University of Korea, Suwon, Republic of Korea \\ Correspondence should be addressed to Sung-Goo Kang; hippo94@naver.com
}

Received 15 April 2016; Revised 29 September 2016; Accepted 24 January 2017; Published 9 February 2017

Academic Editor: Christof Kolb

Copyright @ 2017 Su-Hyun Nam et al. This is an open access article distributed under the Creative Commons Attribution License, which permits unrestricted use, distribution, and reproduction in any medium, provided the original work is properly cited.

\begin{abstract}
Introduction. The neutrophil-lymphocyte ratio (NLR) is a significant systemic predictor of cardiovascular disease (CVD). The coronary artery calcium score (CACS) reflects coronary artery calcification and is an independent risk factor for coronary artery stenosis. In the present study, we explored the relationship between the NLR and CACS in terms of subclinical inflammation and coronary artery calcification. Materials and Methods. We evaluated males and females who did not have CVD, diabetes, high blood pressure, or high fasting blood sugar levels. We measured white blood cell, neutrophil, lymphocyte counts, fasting blood sugar, total cholesterol, high-density lipoprotein cholesterol, triglycerides (TG), and high-sensitivity C-reactive protein levels in blood samples. We also obtained CACSs using coronary multidetector computed tomography. Results. Multivariate logistic regression showed that older age was significantly associated with a higher CACS $(P<0.001)$; males had higher CACSs than females $(P<0.001)$; and the higher the TG level, the higher the CACS $(P=0.019)$. The NLR of males, but not females, was significantly associated with the CACS. Conclusion. An independent association between the NLR and CACS was thus evident in healthy adult males after adjusting for other CVD risk factors. Therefore, the NLR is a significant predictor of potential CVD in male subjects with subclinical atherosclerosis.
\end{abstract}

\section{Introduction}

Coronary artery disease $(\mathrm{CAD})$ caused by atherosclerosis is a leading cause of adult death in developed countries [1]. In South Korea, westernization of eating habits and aging of the population are today associated with high CAD-associated morbidity and mortality. Atherosclerosis is a multifactorial disease involving several cardiovascular risk factors including dyslipidemia, high blood pressure, a high blood glucose level, and smoking. Recent studies have shown that atherosclerosis is not a passive injury caused by deposition of serum lipids and other substances on vascular walls but rather is an active inflammatory process [2]. Leukocytes are activated during inflammation, triggering the development of atherosclerosis and greatly increasing the risk of thrombus formation [3].
The neutrophil-lymphocyte ratio (NLR) (the neutrophil count divided by the lymphocyte count) is easily derived and serves as an indicator of systemic inflammation $[4,5]$. The NLR is prognostic of acute coronary syndrome and is considered a much more reliable predictor than is any other predictor based on leukocyte data $[6,7]$. The NLR is a marker of inflammation and is predictive of death, myocardial infarction, and coronary artery disease $[6,8,9]$. A high NLR is prognostic of atherosclerotic progression [10]. Furthermore, many epidemiological studies have shown that chronic low-grade inflammation, as indicated by the NLR, plays roles in diabetes, hypertension, metabolic syndrome, obesity, dyslipidemia, and endothelial dysfunction [11, 12].

Coronary multidetector computed tomography (MDCT) is a relatively novel method used to diagnose coronary artery 
disease. The coronary artery calcium score (CACS) reflects the extent of calcification of the coronary arteries. The CACS was calculated by the method of Agatston et al., yielding a total CACS that is the sum of the CACSs of each artery [13]. A higher CACS indicates a higher risk of CVD [14]. The CACS is proportional to the extent of atherosclerotic plaque and can predict coronary artery stenosis, another independent predictor of ischemic heart disease $[15,16]$. Calculation of CACSs would assist in reducing the incidence of ischemic heart disease, allowing an early diagnosis of coronary artery atherosclerosis.

Today, the Framingham risk score, which considers various risk factors (age, sex, high blood pressure, the presence of diabetes, dyslipidemia, and smoking), is widely used to evaluate the risk of CVD. However, approximately half of all patients with CVD have either none or one of these risk factors $[17,18]$. As inflammation is associated with atherosclerosis development and progression, we hypothesized that the NLR, considered in combination with other risk factors, aids in the prediction of CVD. Thus, we explored whether the NLR was associated with atherosclerosis measured by the CACS in healthy Korean subjects.

\section{Materials and Methods}

2.1. Study Population. The study subjects were 1,009 adults who underwent complete physical examinations and MDCT in the Health Promotion Center of a general hospital located in Gyeonggi-do, Korea. Of these subjects, those who had cancer, angina pectoris, acute myocardial infarction, and cerebral or peripheral vascular disease were excluded, as were those diagnosed with hypertension or diabetes or who were taking medications to treat these conditions. We performed more than two checkups on all subjects and excluded those who, on any checkup, had a systolic blood pressure $>140 \mathrm{mmHg}$, a diastolic pressure $>90 \mathrm{mmHg}$, and a blood fasting blood sugar level $>126 \mathrm{~mL} / \mathrm{dL}$. Also, subjects with white blood cell (WBC) counts $>10,000 / \mu \mathrm{L}$ were excluded, because they may have had acute infectious disease. Finally, 599 subjects participated in the study.

\subsection{Methods}

2.2.1. Basic Survey and Physical Examination. Before examination, we recorded any history of high blood pressure, diabetes, angina pectoris, or myocardial infarction. Additionally, we noted the medications used, smoking history, drinking history, and exercise habits. Weight and height were estimated to the nearest $100 \mathrm{~g}$ and $1 \mathrm{~cm}$, respectively. BMI was calculated as weight $(\mathrm{kg}) /$ height $^{2}\left(\mathrm{~m}^{2}\right)$. Waist circumference (WC) was measured under the ribs (at the upper midpoint of the crista iliaca) to the nearest $1 \mathrm{~cm}$, with each subject erect, feet $30 \mathrm{~cm}$ apart, and exhaling comfortably. Blood pressure was measured automatically after each subject had been seated for $20 \mathrm{~min}$.

2.2.2. Biochemical Tests. Blood was drawn from the brachial vein the morning after an overnight fast. We measured WBC, neutrophil, and lymphocyte counts and the blood levels of fasting glucose (FBG), total cholesterol, high-density lipoprotein cholesterol, triglycerides (TG), aspartate transaminase, alanine transaminase (ALT), gamma-glutamyl transpeptidase (a-GTP), creatinine, high-sensitivity C-reactive protein, uric acid, calcium, phosphate, and albumin.

2.2.3. CACS. CACSs were calculated from the heart CT scans obtained using the aid of a 64-slice MDCT scanner (Sensation 64; Siemens, Erlangen, Germany). Scans were obtained after at least $6 \mathrm{~h}$ of fasting, with caffeine intake prohibited. If the heart rate of a subject who was not on a betablocker was $>65$ beats per min, we sought to lower the heart rate by giving atenolol $(25-75 \mathrm{mg}) 1 \mathrm{~h}$ before scanning. Using an autoimpregnator, we injected $60-70 \mathrm{~mL}$ nonionic contrast medium (Ultravist 370, Schering, Germany) followed by saline $(40 \mathrm{~mL})$ into the ulnar artery. We electrocardiographically synchronized the heart CT and calculated each CACS via reconstruction (Wizard; Siemens, Erlangen, Germany). CACS was calculated using the method of Agatston. The coronary artery was divided into four segments, and the scores of each segment were calculated and summed. We used the extent of pigmentation to calculate each CACS $(0,>0)$.

2.2.4. Statistics. Data were compared using Statistical Package for the Social Sciences software, version 18.0 (SPSS Inc., Chicago, IL, USA). We compared between-group parameters using the $t$-test. To afford a $95 \%$ predictive power of an odds ratio (OR) of 2 at the 5\% significance level, the twotailed $t$-test indicated that 502 subjects were required [19]. ORs and $95 \%$ confidence intervals (CIs) were calculated by multivariate logistic regression. A $P$ value $<0.05$ was regarded as statistically significant.

2.2.5. Ethics Statement. This study was implemented in accordance with ethical and safety guidelines upon the approval of the Institutional Review Board in The Catholic University of Korea, St. Vincent's Hospital (IRB approval number: VC15RISI0068). The study was exempted from the written informed consent to participants because we reviewed the health screening data and medical record retrogradely. The IRBs approved this consent procedure.

\section{Results}

3.1. General Subject Characteristics. Of the 599 subjects, 473 $(79 \%)$ had a CACS of 0 and $126(21 \%)$ a CACS $>0$. The average age of the latter group was $56.06 \pm 8.99$ years, significantly higher than that of the CACS $=0$ group $(49.09 \pm 56.06$ years; $P<0.001$ ). In the CACS $>0$ group, WC, systolic blood pressure, and levels of ALT, GTP, TC, and TG were significantly higher than those of the CACS $=0$ group. The WBC count and NLR did not differ significantly between the groups (Table 1).

3.2. The Relationship between the CACS and CVD Risk Factors in All Subjects. Multivariate logistic regression was used to explore the relationships between the CACS and factors that might affect the CACS (Table 2). Aging was an 
TABLE 1: Baseline characteristics of study populations.

\begin{tabular}{|c|c|c|c|}
\hline & $\mathrm{CACS}=0$ & CACS $>0$ & $P$ value \\
\hline Age (year) & $49.04 \pm 8.46$ & $56.06 \pm 9.00$ & $<0.001$ \\
\hline Sex & & & $<0.001$ \\
\hline Male & $295(74.3 \%)$ & $102(25.8 \%)$ & \\
\hline Female & $178(88.1 \%)$ & $24(11.9 \%)$ & \\
\hline Smoking & & & 0.912 \\
\hline Nonsmoker & $337(78.7 \%)$ & $91(21.3 \%)$ & \\
\hline Smoker & $136(79.5 \%)$ & $35(20.5 \%)$ & \\
\hline $\operatorname{BMI}\left(\mathrm{kg} / \mathrm{m}^{2}\right)$ & $23.91 \pm 2.70$ & $24.62 \pm 3.20$ & 0.011 \\
\hline $\mathrm{WC}(\mathrm{cm})$ & $84.31 \pm 8.41$ & $86.88 \pm 8.42$ & 0.003 \\
\hline SBP (mmHg) & $119.43 \pm 11.37$ & $122.27 \pm 10.10$ & 0.007 \\
\hline DBP (mmHg) & $72.68 \pm 8.32$ & $72.92 \pm 7.54$ & 0.761 \\
\hline $\mathrm{WBC}\left(10^{3} / \mu \mathrm{L}\right)$ & $5.95 \pm 1.58$ & $6.24 \pm 1.73$ & 0.086 \\
\hline Neutrophils $\left(10^{3} / \mu \mathrm{L}\right)$ & $53.07 \pm 8.78$ & $52.19 \pm 8.16$ & 0.315 \\
\hline Lymphocytes $\left(10^{3} / \mu \mathrm{L}\right)$ & $36.28 \pm 7.70$ & $36.90 \pm 7.88$ & 0.435 \\
\hline Neutrophil-lymphocyte ratio & $1.59 \pm 0.63$ & $1.53 \pm 0.60$ & 0.416 \\
\hline $\mathrm{Hb}$ & $14.78 \pm 1.55$ & $15.05 \pm 1.37$ & 0.059 \\
\hline Albumin & $4.54 \pm 0.29$ & $4.47 \pm 0.39$ & 0.084 \\
\hline FBS (mg/dL) & $92.03 \pm 9.19$ & $95.83 \pm 10.77$ & $<0.001$ \\
\hline $\mathrm{TG}(\mathrm{mg} / \mathrm{dL})$ & $124.83 \pm 72.68$ & $141.77 \pm 72.70$ & 0.020 \\
\hline TC (mg/dL) & $201.98 \pm 35.47$ & $213.47 \pm 64.24$ & 0.008 \\
\hline HDL-C (mg/dL) & $47.24 \pm 11.00$ & $45.40 \pm 9.85$ & 0.090 \\
\hline AST (IU/L) & $22.06 \pm 12.32$ & $24.29 \pm 11.54$ & 0.068 \\
\hline ALT (IU/L) & $25.49 \pm 20.48$ & $30.09 \pm 24.59$ & 0.032 \\
\hline rGTP (IU/L) & $32.78 \pm 33.16$ & $44.85 \pm 52.53$ & 0.015 \\
\hline $\mathrm{Cr}(\mathrm{mg} / \mathrm{dL})$ & $0.84 \pm 0.16$ & $0.97 \pm 0.74$ & 0.061 \\
\hline $\mathrm{UA}(\mathrm{mg} / \mathrm{dL})$ & $5.58 \pm 1.45$ & $5.78 \pm 1.37$ & 0.182 \\
\hline $\mathrm{Ca}$ & $9.09 \pm 0.35$ & $9.96 \pm 8.99$ & 0.317 \\
\hline $\mathrm{P}$ & $3.27 \pm 0.47$ & $3.28 \pm 0.46$ & 0.735 \\
\hline Ca/P Ratio & $2.84 \pm 0.42$ & $3.13 \pm 3.27$ & 0.360 \\
\hline hsCRP (mg/dL) & $0.15 \pm 0.35$ & $0.20 \pm 0.29$ & 0.195 \\
\hline
\end{tabular}

independent risk factor for an elevated CACS; as subject age increased, the CACS rose significantly $(P<0.001)$. Males had higher CACSs than those of females, and, as the TG level increased, the CACS increased significantly $(P=0.019)$ (Table 2)

3.3. The Relationship between the CACS and CVD Risk Factors in Males. We used multivariate logistic regression to evaluate 397 males in terms of the relationships between the CACS and factors that might affect the CACS. The CACS increased significantly $(P<0.001)$ with the age of healthy asymptomatic males and was also significantly associated with elevated systolic blood pressure $(P=0.039)$. Of the hematological factors evaluated, the NLR was found to be an independent risk factor for an elevated CACS; the CACS increased significantly with the NLR $(P=0.045)$. Of the lipid-related factors, the higher the TG level, the higher the CACS $(P=0.022)$ (Table 3$)$. After adjusting other factors, area under the ROC curve of NLR in predicting CAC was 0.74 (95\% CI $=0.66-0.82)$ (Figure 1$)$.
3.4. The Relationship between the CACS and CVD Factors in Females. Of all 136 women, age $(P<0.001)$, body mass index $(P=0.011)$, and current smoking status $(P=$ 0.002 ) independently and significantly affected the CACS. No significant relationship was evident between the NLR and CACS in females (Table 4).

\section{Discussion}

We explored the relationship between the NLR and the CACS to determine if the NLR (a measure of subclinical inflammation) predicted the extent of coronary artery calcification in asymptomatic subjects. For healthy males (but not females), an increase in the NLR was correlated independently with an increase in the CACS.

Inflammation plays critical roles in many coronary artery diseases [20]. Atherosclerosis is a complex of inflammatory diseases [21]. Leukocytes contribute substantially to progression of inflammation [22], and several prospective studies have found positive correlations between leukocyte 
TABLE 2: Odds ratios and 95\% intervals for CACS in men and women in multivariate analysis.

\begin{tabular}{|c|c|c|c|c|}
\hline \multirow{2}{*}{ Variables } & \multirow{2}{*}{ OR } & \multicolumn{2}{|c|}{$95 \% \mathrm{CI}$} & \multirow{2}{*}{$P$ value } \\
\hline & & Lower & Upper & \\
\hline Age (year) & 1.166 & 1.101 & 1.234 & $<0.001$ \\
\hline Female & 0.048 & 0.010 & 0.226 & $<0.001$ \\
\hline Current smoker & 0.601 & 0.221 & 1.633 & 0.318 \\
\hline BMI $\left(\mathrm{kg} / \mathrm{m}^{2}\right)$ & 1.207 & 0.946 & 1.539 & 0.130 \\
\hline $\mathrm{WC}(\mathrm{cm})$ & 0.934 & 0.854 & 1.022 & 0.136 \\
\hline SBP (mmHg) & 1.041 & 0.987 & 1.098 & 0.135 \\
\hline DBP (mmHg) & 0.961 & 0.895 & 1.032 & 0.271 \\
\hline $\mathrm{WBC}\left(10^{3} / \mu \mathrm{L}\right)$ & 0.960 & 0.710 & 1.299 & 0.793 \\
\hline Neutrophils $\left(10^{3} / \mu \mathrm{L}\right)$ & 1.062 & 0.936 & 1.205 & 0.353 \\
\hline Lymphocytes $\left(10^{3} / \mu \mathrm{L}\right)$ & 1.101 & 0.938 & 1.279 & 0.208 \\
\hline Neutrophil-lymphocyte ratio & 2.209 & 0.222 & 21.938 & 0.499 \\
\hline Hemoglobin & 0.652 & 0.439 & 0.967 & 0.034 \\
\hline Albumin & 0.176 & 0.031 & 0.995 & 0.049 \\
\hline FBS (mg/dL) & 0.993 & 0.951 & 1.037 & 0.760 \\
\hline $\mathrm{TC}(\mathrm{mg} / \mathrm{dL})$ & 0.999 & 0.990 & 1.009 & 0.854 \\
\hline HDL-C (mg/dL) & 1.001 & 0.959 & 1.044 & 0.975 \\
\hline TG (mg/dL) & 1.008 & 1.001 & 1.014 & 0.019 \\
\hline AST (IU/L) & 1.076 & 1.008 & 1.147 & 0.027 \\
\hline ALT (IU/L) & 0.997 & 0.960 & 1.035 & 0.870 \\
\hline rGTP (IU/L) & 0.994 & 0.981 & 1.008 & 0.415 \\
\hline $\mathrm{Cr}(\mathrm{mg} / \mathrm{dL})$ & 2.261 & 0.422 & 12.119 & 0.341 \\
\hline UA (mg/dL) & 1.077 & 0.794 & 1.461 & 0.635 \\
\hline $\mathrm{Ca}$ & 1.912 & 0.362 & 3.388 & 0.315 \\
\hline $\mathrm{P}$ & 0.642 & 0.008 & 5.640 & 0.843 \\
\hline $\mathrm{Ca} / \mathrm{P}$ ratio & 0.759 & 0.006 & 9.762 & 0.910 \\
\hline hsCRP (mg/dL) & 1.078 & 0.340 & 3.411 & 0.899 \\
\hline
\end{tabular}

TABLE 3: Odds ratios and 95\% intervals for CACS in men in multivariate analysis.

\begin{tabular}{|c|c|c|c|c|}
\hline \multirow{2}{*}{ Variables } & \multirow{2}{*}{ OR } & \multicolumn{2}{|c|}{$95 \% \mathrm{CI}$} & \multirow{2}{*}{$P$ value } \\
\hline & & Lower & Upper & \\
\hline Age (year) & 1.154 & 1.077 & 1.237 & $<0.001$ \\
\hline Current smoker & 0.499 & 0.159 & 1.565 & 0.233 \\
\hline BMI $\left(\mathrm{kg} / \mathrm{m}^{2}\right)$ & 1.024 & 0.735 & 1.428 & 0.887 \\
\hline $\mathrm{WC}(\mathrm{cm})$ & 0.946 & 0.839 & 1.066 & 0.362 \\
\hline SBP (mmHg) & 1.076 & 1.004 & 1.153 & 0.039 \\
\hline DBP (mmHg) & 0.924 & 0.846 & 1.010 & 0.083 \\
\hline $\mathrm{WBC}\left(10^{3} / \mu \mathrm{L}\right)$ & 0.874 & 0.600 & 1.275 & 0.485 \\
\hline Neutrophils $\left(10^{3} / \mu \mathrm{L}\right)$ & 0.956 & 0.845 & 1.083 & 0.479 \\
\hline Lymphocytes $\left(10^{3} / \mu \mathrm{L}\right)$ & 1.148 & 0.966 & 1.365 & 0.118 \\
\hline Neutrophil-lymphocyte ratio & 7.464 & 1.047 & 53.212 & 0.045 \\
\hline Hemoglobin & 0.584 & 0.343 & 0.993 & 0.047 \\
\hline Albumin & 0.368 & 0.052 & 2.602 & 0.317 \\
\hline FBS (mg/dL) & 0.970 & 0.921 & 1.022 & 0.257 \\
\hline $\mathrm{TC}(\mathrm{mg} / \mathrm{dL})$ & 1.004 & 0.994 & 1.014 & 0.445 \\
\hline HDL-C (mg/dL) & 0.976 & 0.922 & 1.020 & 0.416 \\
\hline $\mathrm{TG}(\mathrm{mg} / \mathrm{dL})$ & 1.011 & 1.001 & 1.020 & 0.022 \\
\hline AST (IU/L) & 1.095 & 1.007 & 1.189 & 0.033 \\
\hline ALT (IU/L) & 0.984 & 0.940 & 1.030 & 0.487 \\
\hline rGTP (IU/L) & 0.991 & 0.974 & 1.007 & 0.256 \\
\hline $\mathrm{Cr}(\mathrm{mg} / \mathrm{dL})$ & 2.240 & 0.506 & 9.918 & 0.288 \\
\hline $\mathrm{UA}(\mathrm{mg} / \mathrm{dL})$ & 0.988 & 0.693 & 1.409 & 0.948 \\
\hline $\mathrm{Ca}$ & 3.376 & 0.241 & 47.210 & 0.366 \\
\hline $\mathrm{P}$ & 10.477 & 0.028 & 39.128 & 0.437 \\
\hline $\mathrm{Ca} / \mathrm{P}$ ratio & 8.464 & 0.241 & 47.210 & 0.507 \\
\hline hsCRP (mg/dL) & 3.251 & 0.385 & 27.422 & 0.279 \\
\hline
\end{tabular}




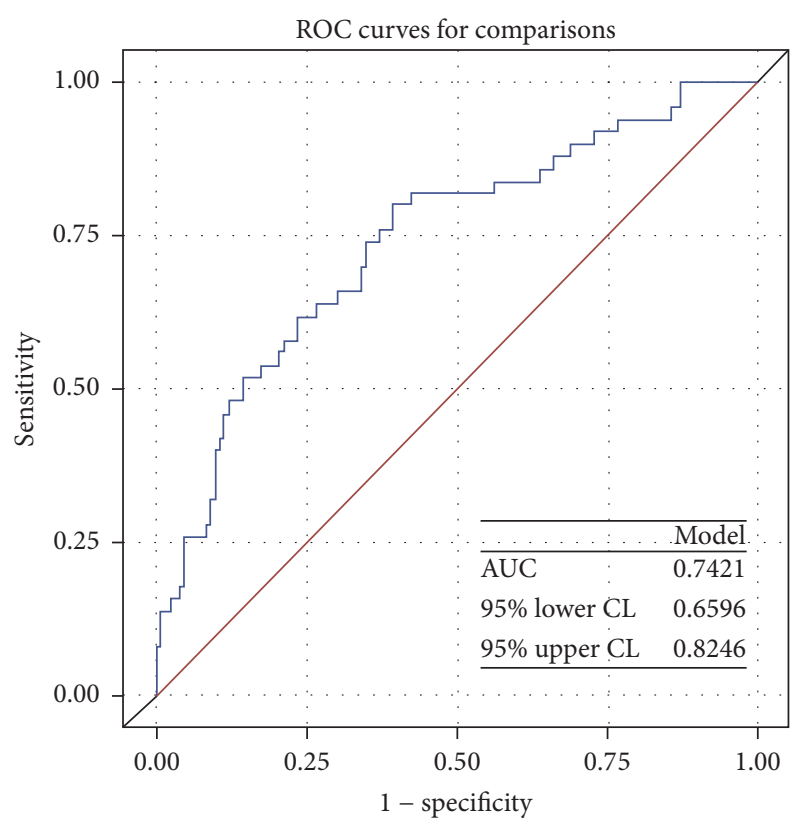

FIGURE 1: The graphs represent area under the ROC curve (AUC) of NLR in predicting CAC in men. Model was adjusted with age, smoking, BMI, WC, SBP, DBP, WBC, Hb, albumin, FBS, TC, HDL$\mathrm{C}$, TG, AST, ALT, rGTP, Cr, Uric acid, $\mathrm{Ca}, \mathrm{P}, \mathrm{Ca} / \mathrm{P}$ ratio, and hs-CRP.

(total and differential) counts and the development of CVD in both adult males and females [23, 24]. The NLR is a well-recognized biomarker of inflammation [25]. When the WBC count is within the normal range, a higher NLR is indicative of a greater risk of atherosclerotic disease [6]. The NLR is associated with other clinical inflammatory markers. Balta et al. reported that there were moderate positive correlations between carotid intima media thickness value, C-reactive protein, and NLR in patients with Behçet disease [26]. Unlike many other inflammatory markers, the NLR is inexpensive and readily available and it provides additional risk stratification beyond conventional risk scores [27]. However, NLR values may be changed by medications. Fici et al. reported that nebivolol improved NLR to a greater extent than metoprolol in patients with hypertension [28].

Balta et al. found that increased NLR may play a role not only in the pathogenesis of coronary artery disease but also in the pathophysiology of coronary artery ectasia [29]. Additionally, the NLR is associated with both the risk and severity of CVD [30]. Shen et al. found that the NLR significantly predicted long-term mortality in 551 STEMI patients who underwent early cardiac revascularization (hazard ratio 2.27 , 95\% CI 1.32-4.29; $P=0.002$ ) [31]. Wang et al. performed a meta-analysis of 10 cohort studies on patients who underwent angiography or cardiac revascularization; the relative risk (RR) of all-cause mortality in the high-NLR group was 2.33 (95\% CI 1.88-2.88), and the RR of a cardiovascular event was 1.89 (95\% CI 1.88-2.88). Thus the NLR significantly predicted both all-cause mortality and cardiovascular events in patients with CVD [32].
Coronary artery calcification is closely associated with coronary artery disease [33]. The CACS reflects both the extent and distribution of coronary artery calcification, which reliably predicts the CVD risk [34-36]. As calcium deposits increase, so does the CVD risk [37]. One systematic study found that when the CACS was 0 , the prevalence of CVD was $0.56 \%$, and the negative predictive value $99 \%$ (thus very high) [38]. When the CACS was $<100$, the risk of an angiographic diagnosis of significant coronary artery stenosis $(>50 \%)$ was $<3 \%$ [39]. In a 3-year study on 2,000 asymptomatic adults, a CAC $>0$ increased the risk of CVD 10.5-fold in males and 2.6-fold in females [40].

Turkmen et al. evaluated 56 patients (34 males, 22 females) with end-stage renal disease who were on dialysis for $>6$ months. Except for in those with acute infections, autoimmune diseases, acute heart failure, or CVD, the NLR and CACS were significantly correlated $(r=0.3, P=$ 0.02) [41]. Also, in a study of 290 patients with type 2 diabetes mellitus, those with NLRs $\leq 2.05$ had lower CACSs and a lower incidence of obstructive coronary artery disease than did those with NLRs >2.05 [42]. Park et al. used multivariate logistic regression to show that a high NLR was independently associated with an elevated CACS in 849 Koreans [43]. The cited work included patients with hypertension and diabetes, and the data were not analyzed by sex. We excluded patients with diabetes or hypertension and showed that the NLR was correlated independently with the CACS (after adjustment for other CVD risk factors) of healthy adult males with FBG levels $<126 \mathrm{mg} / \mathrm{dL}$, systolic blood pressure $<140 \mathrm{mmHg}$, and diastolic blood pressure $<90 \mathrm{~mm} \mathrm{Hg}$. Therefore, the NLR can be used to predict CVD not only in patients at high risk of CVD (such as those with diabetes, hypertension, and chronic renal failure) but also in asymptomatic healthy adult males.

We found that the TG level was independently associated with the CACS, in agreement with the data of Cao et al. [44]. Tirosh et al. evaluated 13,953 healthy adult males aged 26-45 years for 5 years and found a strong correlation between the TG level and the development of CVD [45]. A meta-analysis of studies on adults of mean age of 56.6 years, over a 12-year follow-up, found that the CVD risk was 1.8-fold greater in those with the highest $20 \%$ of TG levels, compared with those with the lowest 20\% [46]. Also, in the Framingham study, the risk of CVD was 2-fold higher in those with TG levels of $250-400 \mathrm{mg} / \mathrm{dL}$ than in those with TG levels of $50-100 \mathrm{mg} / \mathrm{dL}$ [47]. The Copenhagen study recruited middle-aged males ( $>54$ years of age). In those with TG levels $>142 \mathrm{mg} / \mathrm{dL}$, the adjusted RR of CVD was 2.2, significantly higher than the RRs of those with lower TG levels [48]. Tirosh et al. showed that elevated TG levels correlated significantly with the body mass index, the extent of physical activity, and breakfast habits [45]. Therefore, lifestyle-mediated management of TG levels will greatly lower the CVD risk.

We found a close association between female smoking and the CACS. Lehmann et al. reported that current smoking was an independent risk factor for a CACS $>0$, and that the time until reaching a CACS $>0$ was approximately 10 years less in current versus former smokers [49]. Smoking lowers the availability of nitrogen oxide, triggering endothelial and 
TABLE 4: Odds ratios and 95\% intervals for CACS in women in multivariate analysis.

\begin{tabular}{|c|c|c|c|c|}
\hline \multirow{2}{*}{ Variables } & \multirow{2}{*}{ OR } & \multicolumn{2}{|c|}{$95 \% \mathrm{CI}$} & \multirow{2}{*}{$P$ value } \\
\hline & & Lower & Upper & \\
\hline Age (year) & 1.303 & 1.138 & 1.492 & $<0.001$ \\
\hline Current smoker & 99.872 & 5.450 & 1830.127 & 0.002 \\
\hline $\operatorname{BMI}\left(\mathrm{kg} / \mathrm{m}^{2}\right)$ & 1.735 & 1.135 & 2.654 & 0.011 \\
\hline $\mathrm{WC}(\mathrm{cm})$ & 0.907 & 0.822 & 1.001 & 0.052 \\
\hline SBP (mmHg) & 1.008 & 0.922 & 1.101 & 0.867 \\
\hline $\mathrm{DBP}(\mathrm{mmHg})$ & 0.943 & 0.823 & 1.080 & 0.394 \\
\hline Neutrophils $\left(10^{3} / \mu \mathrm{L}\right)$ & 1.204 & 0.954 & 1.519 & 0.117 \\
\hline Lymphocytes $\left(10^{3} / \mu \mathrm{L}\right)$ & 0.798 & 0.596 & 1.067 & 0.128 \\
\hline Neutrophil-lymphocyte ratio & 0.010 & 0.000 & 2.585 & 0.104 \\
\hline Hemoglobin & 0.748 & 0.391 & 1.432 & 0.381 \\
\hline FBS (mg/dL) & 1.052 & 0.972 & 1.139 & 0.211 \\
\hline $\mathrm{TC}(\mathrm{mg} / \mathrm{dL})$ & 1.012 & 0.989 & 1.036 & 0.314 \\
\hline HDL-C (mg/dL) & 0.977 & 0.905 & 1.055 & 0.553 \\
\hline $\mathrm{TG}(\mathrm{mg} / \mathrm{dL})$ & 0.989 & 0.977 & 1.002 & 0.095 \\
\hline AST (IU/L) & 0.253 & 0.728 & 1.087 & 0.253 \\
\hline ALT (IU/L) & 1.155 & 0.988 & 1.350 & 0.071 \\
\hline rGTP (IU/L) & 0.975 & 0.926 & 1.027 & 0.348 \\
\hline UA (mg/dL) & 0.567 & 0.239 & 1.344 & 0.198 \\
\hline $\mathrm{Ca}$ & 6.326 & 0.291 & 12.826 & 0.167 \\
\hline $\mathrm{P}$ & 0.163 & 0.000 & 13.897 & 0.694 \\
\hline $\mathrm{Ca} / \mathrm{P}$ ratio & 0.216 & 0.000 & 17.147 & 0.791 \\
\hline
\end{tabular}

vasomotor dysfunction, activating leukocyte-endothelial cell interactions, triggering leucocyte recruitment, increasing the levels of proatherogenic substances by elevating proinflammatory cytokine levels, and triggering oxidative lipid modifications, culminating in atherosclerosis [50].

Our study had a few limitations. First, we considered only present smoking status; we did not record pack-years, and we did not consider alcohol ingestion, self-reporting bias, or stress associated with smoking. Thus, we found no relationship between smoking and the CACS in males. Had we considered the above factors, such an association might have become apparent. Second, our work was cross-sectional in nature; caution is thus appropriate when seeking to identify causative relationships.

In conclusion, we found an independent correlation between the NLR and the CACS in asymptomatic Korean adult males. The NLR can be used to predict CVD in subjects with subclinical atherosclerosis.

\section{Competing Interests}

The authors declare that there is no conflict of interests.

\section{References}

[1] R. Beaglehole, "Global cardiovascular disease prevention: time to get serious," The Lancet, vol. 358, no. 9282, pp. 661-663, 2001.

[2] M. Drechsler, R. T. A. Megens, M. Van Zandvoort, C. Weber, and O. Soehnlein, "Hyperlipidemia-triggered neutrophilia promotes early atherosclerosis," Circulation, vol. 122, no. 18, pp. 1837-1845, 2010.
[3] D. Ganguli, N. Das, I. Saha et al., "Association between inflammatory markers and cardiovascular risk factors in women from Kolkata, W.B, India," Arquivos Brasileiros de Cardiologia, vol. 96, no. 1, pp. 38-46, 2011.

[4] S. Balta, S. Demirkol, U. Kucuk, H. Sarlak, O. Kurt, and Z. Arslan, "Neutrophil to lymphocyte ratio may predict mortality in breast cancer patients," Journal of Breast Cancer, vol. 16, no. 3, pp. 354-355, 2013.

[5] Y. Arbel, A. Finkelstein, A. Halkin et al., "Neutrophil/lymphocyte ratio is related to the severity of coronary artery disease and clinical outcome in patients undergoing angiography," Atherosclerosis, vol. 225, no. 2, pp. 456-460, 2012.

[6] B. D. Horne, J. L. Anderson, J. M. John et al., "Which white blood cell subtypes predict increased cardiovascular risk?" Journal of the American College of Cardiology, vol. 45, no. 10, pp. 1638-1643, 2005.

[7] U. U. Tamhane, S. Aneja, D. Montgomery, E.-K. Rogers, K. A. Eagle, and H. S. Gurm, "Association between admission neutrophil to lymphocyte ratio and outcomes in patients with acute coronary syndrome," The American Journal of Cardiology, vol. 102, no. 6, pp. 653-657, 2008.

[8] A. Papa, M. Emdin, C. Passino, C. Michelassi, D. Battaglia, and F. Cocci, "Predictive value of elevated neutrophil-lymphocyte ratio on cardiac mortality in patients with stable coronary artery disease," Clinica Chimica Acta, vol. 395, no. 1-2, pp. 27-31, 2008.

[9] M. S. Sabatine, D. A. Morrow, C. P. Cannon et al., "Relationship between baseline white blood cell count and degree of coronary artery disease and mortality in patients with acute coronary syndromes: a TACTICS-TIMI 18 substudy," Journal of the American College of Cardiology, vol. 40, no. 10, pp. 1761-1768, 2002. 
[10] N. Kalay, O. Dogdu, F. Koc et al., "Hematologic parameters and angiographic progression of coronary atherosclerosis," Angiology, vol. 63, no. 3, pp. 213-217, 2012.

[11] S. Balta, E. Kurtoglu, U. Kucuk, S. Demirkol, and C. Ozturk, "Neutrophil-lymphocyte ratio as an important assessment tool," Expert Review of Cardiovascular Therapy, vol. 12, no. 5, pp. 537538, 2014.

[12] M. Karaman, S. Balta, S. A. Ay et al., "The comparative effects of valsartan and amlodipine on vWf levels and N/L ratio in patients with newly diagnosed hypertension," Clinical and Experimental Hypertension, vol. 35, no. 7, pp. 516-522, 2013.

[13] A. S. Agatston, W. R. Janowitz, F. J. Hildner, N. R. Zusmer, M. Viamonte Jr., and R. Detrano, "Quantification of coronary artery calcium using ultrafast computed tomography," Journal of the American College of Cardiology, vol. 15, no. 4, pp. 827-832, 1990.

[14] N. D. Wong, J. C. Hsu, R. C. Detrano, G. Diamond, H. Eisenberg, and J. M. Gardin, "Coronary artery calcium evaluation by electron beam computed tomography and its relation to new cardiovascular events," American Journal of Cardiology, vol. 86, no. 5, pp. 495-498, 2000.

[15] L. J. Shaw, P. Raggi, E. Schisterman, D. S. Berman, and T. Q. Callister, "Prognostic value of cardiac risk factors and coronary artery calcium screening for all-cause mortality," Radiology, vol. 228, no. 3, pp. 826-833, 2003.

[16] M. J. Budoff, L. J. Shaw, S. T. Liu et al., "Long-term prognosis associated with coronary calcification. Observations from a registry of 25,253 patients," Journal of the American College of Cardiology, vol. 49, no. 18, pp. 1860-1870, 2007.

[17] U. N. Khot, M. B. Khot, C. T. Bajzer et al., "Prevalence of conventional risk factors in patients with coronary heart disease," Journal of the American Medical Association, vol. 290, no. 7, pp. 898-904, 2003.

[18] P. Greenland, M. D. Knoll, J. Stamler et al., "Major risk factors as antecedents of fatal and nonfatal coronary heart disease events," The Journal of the American Medical Association, vol. 290, no. 7, pp. 891-897, 2003.

[19] F. Faul, E. Erdfelder, A.-G. Lang, and A. Buchner, "G*Power 3: a flexible statistical power analysis program for the social, behavioral, and biomedical sciences," Behavior Research Methods, vol. 39, no. 2, pp. 175-191, 2007.

[20] G. K. Hansson, "Inflammation, atherosclerosis, and coronary artery disease," New England Journal of Medicine, vol. 352, no. 16, pp. 1626-1695, 2005.

[21] R. Ross, "Atherosclerosis is an inflammatory disease," American Heart Journal, vol. 138, no. 5, pp. S419-S420, 1999.

[22] M. Hoffman, A. Blum, R. Baruch, E. Kaplan, and M. Benjamin, "Leukocytes and coronary heart disease," Atherosclerosis, vol. 172, no. 1, pp. 1-6, 2004.

[23] J. S. Rana, S. M. Boekholdt, P. M. Ridker et al., "Differential leucocyte count and the risk of future coronary artery disease in healthy men and women: the EPIC-Norfolk Prospective Population Study," Journal of Internal Medicine, vol. 262, no. 6, pp. 678-689, 2007.

[24] G. Giugliano, G. Brevetti, S. Lanero, V. Schiano, E. Laurenzano, and M. Chiariello, "Leukocyte count in peripheral arterial disease: a simple, reliable, inexpensive approach to cardiovascular risk prediction," Atherosclerosis, vol. 210, no. 1, pp. 288-293, 2010.

[25] P. H. Gibson, B. H. Cuthbertson, B. L. Croal et al., "Usefulness of neutrophil/lymphocyte ratio as predictor of new-onset atrial fibrillation after coronary artery bypass grafting," The American Journal of Cardiology, vol. 105, no. 2, pp. 186-191, 2010.

[26] S. Balta, T. Celik, D. P. Mikhailidis et al., "The relation between atherosclerosis and the neutrophil-lymphocyte ratio," Clinical and Applied Thrombosis/Hemostasis, vol. 22, no. 5, pp. 405-411, 2014.

[27] C. Ozturk, S. Balta, I. Balta et al., "Neutrophil-lymphocyte ratio and carotid-intima media thickness in patients with behçet disease without cardiovascular involvement," Angiology, vol. 66, no. 3, pp. 291-296, 2014.

[28] F. Fici, T. Celik, S. Balta et al., "Comparative effects of nebivolol and metoprolol on red cell distribution width and neutrophil/lymphocyte ratio in patients with newly diagnosed essential hypertension," Journal of Cardiovascular Pharmacology, vol. 62, no. 4, pp. 388-393, 2013.

[29] S. Balta, S. Demirkol, T. Celik et al., "Association between coronary artery ectasia and neutrophil-lymphocyte ratio," Angiology, vol. 64, no. 8, pp. 627-632, 2013.

[30] M. Verdoia, L. Barbieri, G. Di Giovine, P. Marino, H. Suryapranata, and G. De Luca, "Neutrophil to lymphocyte ratio and the extent of coronary artery disease: results from a large cohort study," Angiology, vol. 67, no. 1, pp. 75-82, 2016.

[31] X.-H. Shen, Q. Chen, Y. Shi, and H.-W. Li, "Association of neutrophil/lymphocyte ratio with long-term mortality after ST elevation myocardial infarction treated with primary percutaneous coronary intervention," Chinese Medical Journal, vol. 123, no. 23, pp. 3438-3443, 2010.

[32] X. Wang, G. Zhang, X. Jiang, H. Zhu, Z. Lu, and L. Xu, "Neutrophil to lymphocyte ratio in relation to risk of all-cause mortality and cardiovascular events among patients undergoing angiography or cardiac revascularization: a meta-analysis of observational studies," Atherosclerosis, vol. 234, no. 1, pp. 206213, 2014.

[33] L. E. Bolick and D. H. Blankenhorn, "A quantitative study of coronary arterial calcification," The American Journal of Pathology, vol. 39, pp. 511-519, 1961.

[34] W. Stanford and B. H. Thompson, "Imaging of coronary artery calcification: its importance in assessing atherosclerotic disease," Radiologic Clinics of North America, vol. 37, no. 2, pp. 257-272, 1999.

[35] K. Nieman, A. Van Der Lugt, P. M. Pattynama, and P. J. De Feyter, "Noninvasive visualization of atherosclerotic plaque with electron beam and multislice spiral computed tomography," Journal of Interventional Cardiology, vol. 16, no. 2, pp. $123-$ 128, 2003.

[36] T. F. Jakobs, B. J. Wintersperger, P. Herzog et al., "Ultra-lowdose coronary artery calcium screening using multislice CT with retrospective ECG gating," European Radiology, vol. 13, no. 8, pp. 1923-1930, 2003.

[37] M. J. Budoff and K. M. Gul, "Expert review on coronary calcium," Vascular Health and Risk Management, vol. 4, no. 2, pp. 315-324, 2008.

[38] A. Sarwar, L. J. Shaw, M. D. Shapiro et al., "Diagnostic and prognostic value of absence of coronary artery calcification," JACC: Cardiovascular Imaging, vol. 2, no. 6, pp. 675-688, 2009.

[39] M. J. Budoff, G. A. Diamond, P. Raggi et al., "Continuous probabilistic prediction of angiographically significant coronary artery disease using electron beam tomography," Circulation, vol. 105, no. 15, pp. 1791-1796, 2002.

[40] A. J. Taylor, J. Bindeman, I. Feuerstein, F. Cao, M. Brazaitis, and P. G. O'Malley, "Coronary calcium independently predicts 
incident premature coronary heart disease over measured cardiovascular risk factors: mean three-year outcomes in the Prospective Army Coronary Calcium (PACC) project," Journal of the American College of Cardiology, vol. 46, no. 5, pp. 807-814, 2005.

[41] K. Turkmen, F. Ozcicek, A. Ozcicek, E. M. Akbas, F. M. Erdur, and H. Z. Tonbul, "The relationship between neutrophil-tolymphocyte ratio and vascular calcification in end-stage renal disease patients," Hemodialysis International, vol. 18, no. 1, pp. 47-53, 2014.

[42] F. Aygün and D. Efe, "Association of neutrophil/lymphocyte ratio with obstructive coronary artery disease and coronary artery calcium score detected by multislice computed tomography in type 2 diabetes mellitus patients," Patient Preference and Adherence, vol. 9, pp. 1023-1031, 2015.

[43] B. J. Park, J. Y. Shim, H. R. Lee et al., "Relationship of neutrophillymphocyte ratio with arterial stiffness and coronary calcium score," Clinica Chimica Acta, vol. 412, no. 11-12, pp. 925-929, 2011.

[44] H.-L. Cao, X.-B. Chen, J.-G. Lu et al., "Metabolic syndrome and coronary artery calcification: A Community-based Natural Population Study," Chinese Medical Journal, vol. 126, no. 24, pp. 4618-4623, 2013.

[45] A. Tirosh, A. Rudich, T. Shochat et al., "Changes in triglyceride levels and risk for coronary heart disease in young men," Annals of Internal Medicine, vol. 147, no. 6, pp. 377-385, 2007.

[46] A. Patel, F. Barzi, K. Jamrozik et al., "Serum triglycerides as a risk factor for cardiovascular diseases in the Asia-Pacific region," Circulation, vol. 110, no. 17, pp. 2678-2686, 2004.

[47] W. P. Castelli, "Epidemiology of triglycerides: a view from Framingham," The American Journal of Cardiology, vol. 70, no. 19, pp. H3-H9, 1992.

[48] J. Jeppesen, H. O. Hein, P. Suadicani, and F. Gyntelberg, "Triglyceride concentration and ischemic heart disease: an eight-year follow-up in the Copenhagen Male Study," Circulation, vol. 97, no. 11, pp. 1029-1036, 1998.

[49] N. Lehmann, S. Möhlenkamp, A. A. Mahabadi et al., "Effect of smoking and other traditional risk factors on the onset of coronary artery calcification: results of the Heinz Nixdorf recall study," Atherosclerosis, vol. 232, no. 2, pp. 339-345, 2014.

[50] J. A. Ambrose and R. S. Barua, "The pathophysiology of cigarette smoking and cardiovascular disease: an update," Journal of the American College of Cardiology, vol. 43, no. 10, pp. 1731-1737, 2004. 


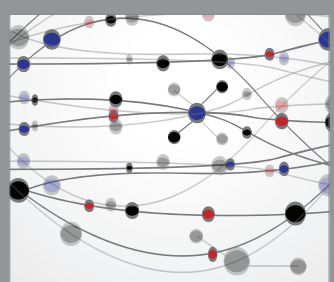

The Scientific World Journal
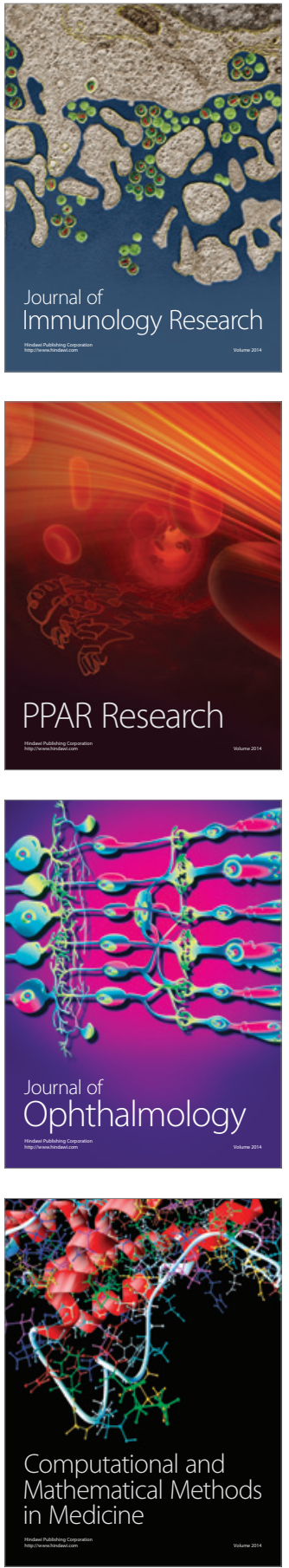

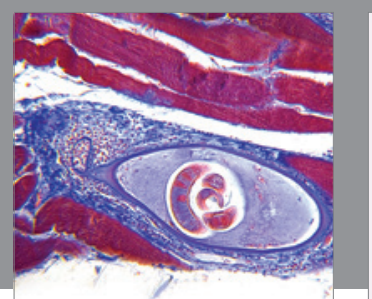

Gastroenterology Research and Practice
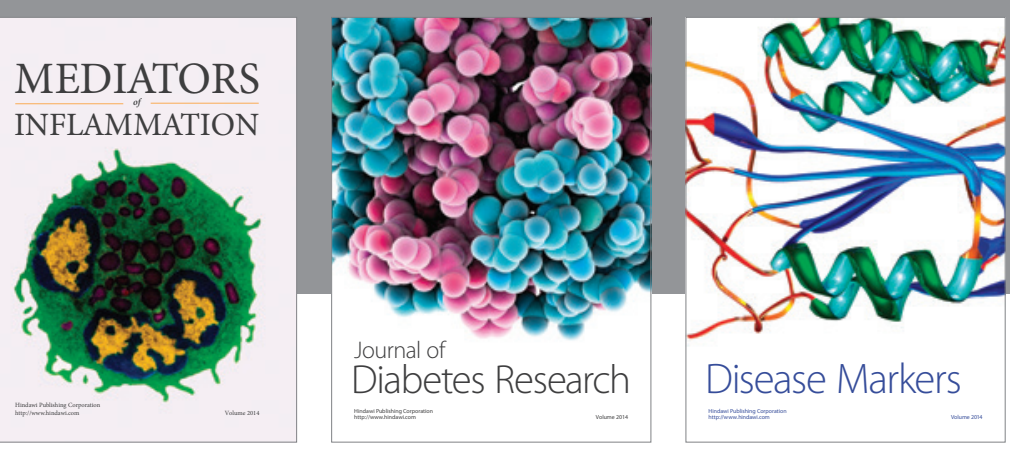

Disease Markers

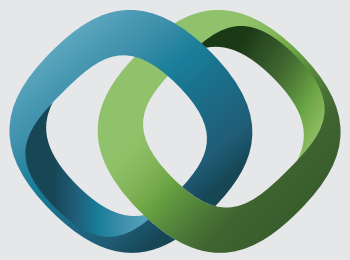

\section{Hindawi}

Submit your manuscripts at

https://www.hindawi.com
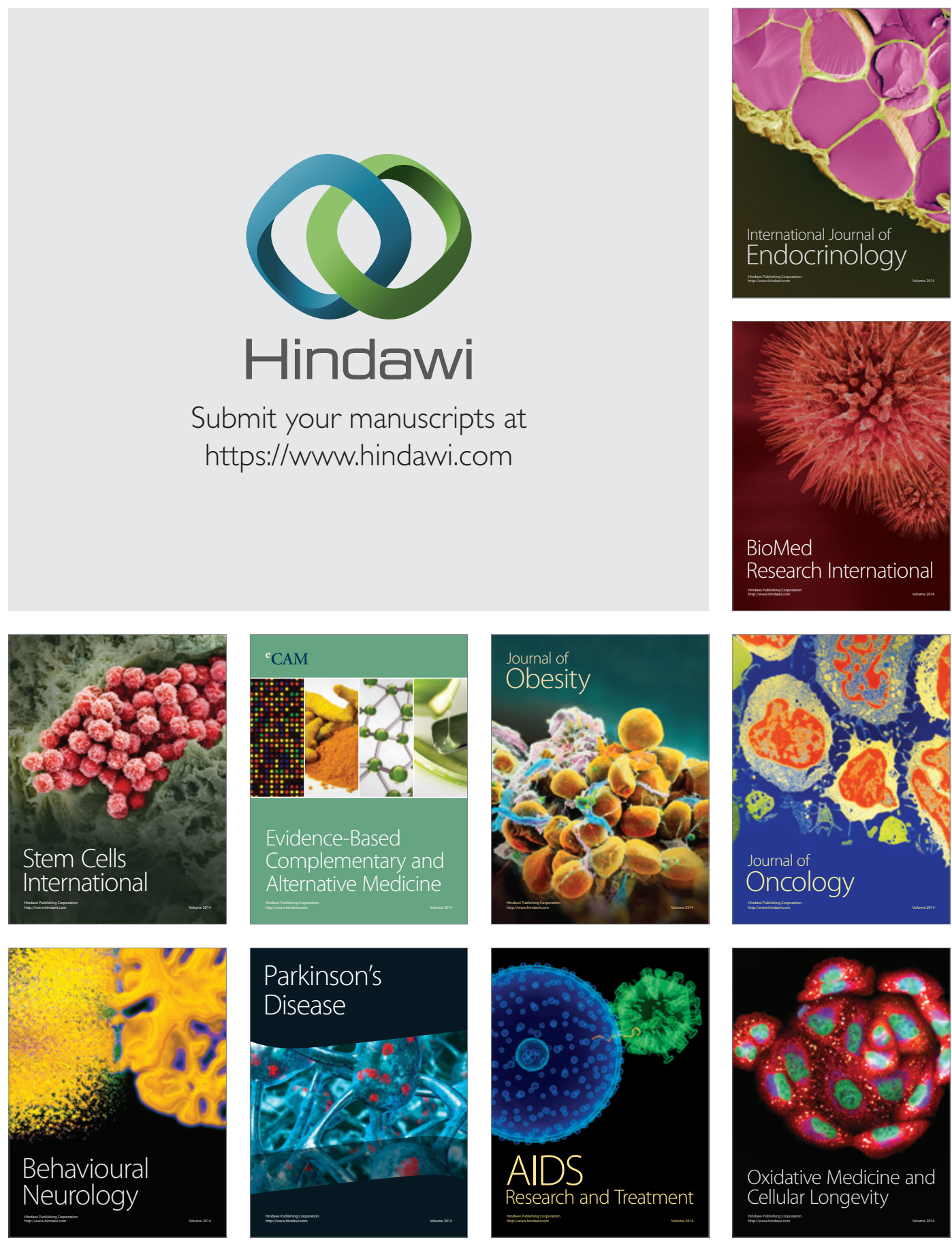